\title{
An Integrated Crop Model and GIS Decision Support System for Assisting Agronomic Decision Making under Climate Change \\ MDM Kadiyala ${ }^{a^{*}}$, S. Nedumaran ${ }^{a}$. Piara Singh ${ }^{a}$, Chukka $S^{a}$, Irshad Mohammad $A^{a}$, MCS Bantilan ${ }^{a}$ \\ ${ }^{a}$ International Crops Research Institute for Semi-Arid Tropics (ICRISAT), Patancheru, Hyderabad, India- 502324
}

Keywords: DSSAT, Crop Simulation, Yield, Virtual cultivars, Climate change factors

* Corresponding author. Tel.: +91 9618956219, fax: +91 4030713334

E-mail address: d.kadiyala@cgiar.org 
An Integrated Crop Model and GIS Decision Support System for Assisting Agronomic Decision Making under Climate Change

\section{Abstract}

The semi-arid tropical (SAT) regions of India are suffering from low productivity which may be further aggravated by anticipated climate change. The present study analyzes the spatial variability of climate change impacts on groundnut yields in the Anantapur district of India and examines the relative contribution of adaptation strategies. For this purpose, a web based decision support tool that integrates crop simulation model and Geographical Information System (GIS) was developed to assist agronomic decision making and this tool can be scalable to any location and crop. The climate change projections of five global climate models (GCMs) relative to the $1980-2010$ baseline for Anantapur district indicates an increase in rainfall activity to the tune of 10.6 to $25 \%$ during Mid-century period (2040-69) with RCP 8.5. The GCMs also predict warming exceeding 1.4 to $2.4{ }^{\circ} \mathrm{C}$ by 2069 in the study region. The spatial crop responses to the projected climate indicate a decrease in groundnut yields with four GCMs (MPI-ESMMR, MIROC5, CCSM4 and HadGEM2-ES) and a contrasting 6.3\% increase with the GCM, GFDL-ESM2M. The simulation studies using CROPGRO-Peanut model reveals that groundnut yields can be increased on average by $1.0 \%, 5.0 \%, 14.4 \%$, and $20.2 \%$, by adopting adaptation options of heat tolerance, drought tolerant cultivars, supplemental irrigation and a combination of drought tolerance cultivar and supplemental irrigation respectively. The spatial patterns of relative benefits of adaptation options were geographically different and the greatest benefits can be 
25 achieved by adopting new cultivars having drought tolerance and with the application of 26 one supplemental irrigation at 60 days after sowing.

27

28

29

30

31

32

33

34

35

36

41

42

43 


\section{INTRODUCTION}

Climate change is one of the most important challenges being faced by humanity that has serious implications on global food security. Its impacts have already been significant on water resources, length of growing season, and food security, especially in the Semi-Arid Tropical regions (IPCC 2007). The climate model projections based on the Inter-Governmental Panel on Climate Change (IPCC) Fifth Coupled Model Intercomparison Project (CMIP5), reveal that surface air temperatures including night time temperatures are expected to further increase compared to the base line conditions (IPCC 2014) Under the business-as-usual scenario, mean warming over India is likely to be in the $1.7-2.0^{\circ} \mathrm{C}$ range by the $2030 \mathrm{~s}$ and in the $3.3-4.8^{\circ} \mathrm{C}$ range by the 2080 s relative to pre-industrial times. All-India rainfall under the business-as-usual scenario, is projected to increase from $4 \%$ to $5 \%$ by 2030 s and from $6 \%$ to $14 \%$ towards the end of the century (2080s) compared to the 1961-1990 baseline (Chaturvedi et al., 2012). Over the past 20th century, in the temperate regions of northern hemisphere average rainfall increased with more frequent extreme heavy rainfall events and in contrast rainfall in sub tropics decreased and droughts have become more intensive and frequent in Asia and Africa (IPCC 2007).

60 Climate change in terms of changes in temperature, rainfall patterns, and increased 61 carbon dioxide $\left(\mathrm{CO}_{2}\right)$ levels will impact agriculture, especially in the rainfed regions. 62 Crop productivity is expected to alter due to these changes in climate, extreme weather 63 events and changed scenario of pests and diseases. Increased carbon dioxide 64 concentration in the atmosphere is beneficial for plant growth, and controlled 65 experiments have demonstrated that elevated $\mathrm{CO}_{2}$ concentrations can increase plant 
66 growth while enhancing water use efficiency (Walthall et al, 2012). The impacts of

67 climate change on agriculture will differ across locations. Determining how climate

68 change will affect agriculture is highly uncertain and complex as a variety of effects are 69 likely to occur (Roudier et al, 2011, Knox et al., 2012, Muller et al., 2011). Production 70 practices may require major adjustments. Adaptation measures such as developing 71 drought, pest, and heat tolerant cultivars, diversifying crop rotations, integrating 72 livestock into crop production systems, and nutrient efficient systems may be required to 73 minimize impacts on productivity. Therefore, determining the location- specific impacts 74 of climate change on crop production and water resources is essential in order to 75 develop possible adaptation strategies (Howden et al ., 2007, Lobell et al 2008., 76 Thornton et al 2009, Godfray et al., 2010)

77 Groundnut (Arachis hypogaea L.) is an important oilseed crop grown by small and 78 marginal farmers. In India the crop is mainly grown under rainfed conditions during the 79 main rainy season (June-October). As climate change becoming more intense and 80 demand for edible oil and vegetable protein in India is increasing, the groundnut 81 production needs to be improved to meet the future demand. This can be possible only 82 by developing new agronomic technologies and cultivars which has greater tolerance to 83 elevated temperatures and responsive to raising $\mathrm{CO}_{2}$.

84 Crop simulation models are valuable tools for evaluating the potential effects of 85 environmental, biological and management factors on crop growth and development. 86 They have been evaluated and used for many soil and environmental conditions across 87 the world and have in the past, been successfully used in yield predictions (Jagtap and 88 Jones, 2002), irrigation planning for crops (Behera and Panda, 2009), optimization of 
89 irrigation water use (Fortes et al., 2005; Bulatewicz et al., 2009), understanding the 90 climate change impacts on various crops (Krishnan et al., 2007, You et al., 2009, 91 Reidsma et al 2010, Singh et al $2014^{\mathrm{a}}$ ). They have also been used for comparison of 92 various scenarios and strategies such as quantifying the potential benefits of 93 incorporating drought, heat tolerance and yield-enhancing traits into commonly grown 94 cultivars under climate change in chickpea (Singh et al 2102, Singh et al 2014 ${ }^{\mathrm{a}}$, Singh 95 et al $2014^{\mathrm{b}}$, Rinaldi, 2004; Rinaldi et al., 2007), analysis of yield trends over time (Liu et 96 al., 2011), and in many more applications. Crop simulation models need to be applied at 97 larger scales to be economically useful so that the effects of various alternate 98 management strategies across the watershed or the region (Naersh Kumar et al., 2013, 99 Mishra et al., 2013). Global studies on linking crop models with a Geographical 100 Information System (GIS) have demonstrated the strong feasibility of crop modeling 101 applications at a spatial scale. Most agricultural operations closely connected with 102 natural resources that vary spatially and GIS, which is capable of using spatial data, can 103 be very handy in environmental and agricultural modeling. Several researchers have 104 successfully used crop models and GIS to study spatial water requirement of crops, 105 yield forecasting and climate change impacts at watershed and regional scales. The 106 objectives of the present study were to quantify the spatial variability in groundnut yields 107 under (a) current climate, (b) climate change and (iii) to provide strategies of cultivar, 108 water and fertilizer application aimed at enhancing production or reducing investment 109 inputs in groundnut under climate change conditions 


\section{Material and Methods}

\subsection{Study area}

112

113

114

131 Anantapur district can be divided into four natural divisions based on soil types, 132

The study area of Anantapur district is in the state of Andhra Pradesh in India. It lies between 13'-40' and 15'-15' Northern Latitude and 76'-50' and 78'-30' Eastern Longitude. It is skirted by Bellary and Kurnool district on the North, Kadapa district to the southeast, and Kolar district to the North (Fig 1). Agriculture is the most important economic activity and source of livelihood in the district. Anantapur is the only arid district in the State with an annual mean rainfall of $598 \mathrm{~mm}(1980-2010)$ with a coefficient of variation (CV) of $28 \%$. The higher $\mathrm{CV}$ of rainfall relative to the threshold level of $25 \%$ for annual rainfall suggests variability and a lower degree of dependability on rainfall. Alfisols are the predominant soils ( $78 \%$ of the area), followed by Vertic Inceptisols (20\%), and other soils are (2\%). The soils based on soil texture can be classified as sandy loams (31\%), clay (24\%) loamy sands (14\%), sandy clay loams (13\%) and rocky lands (12\%). Groundnut (Arachis hypogaea L.) is an important oilseed and food crop grown by small and marginal farmers in the district. Its yields have often been unpredictable due to low and erratic distribution of rainfall coupled with many other biotic factors. Average pod yield was observed to be $516 \mathrm{~kg} / \mathrm{ha}$ and varies between a little over $200 \mathrm{~kg} / \mathrm{ha}$ and $1200 \mathrm{~kg} / \mathrm{ha}$ from year to year. Evidence from earlier studies reveals that in years when seasonal rainfall was $10 \%$ less than normal, yields were reduced drastically by $42 \%$ (Rao et al., 2011). In addition to these problems climate change poses a new threat to the groundnut cultivation in Anantapur. 
region with 24 mandals, Highland region with 12 mandals and Southern region with 13 mandals

\subsection{System Inputs}

\subsubsection{Climate Data}

Thirty-years (1980-2010) of observed daily weather data were obtained from the ANGR Agricultural University Agromet observatory located at Anantapur. The baseline weather datasets were quality controlled and inspected for outliers or anomalous values and if found, such values were adjusted and corrected using bias corrected AgMERRA data. AgMERRA consists of historical climate datasets, which were prepared based on a combination of daily outputs from retrospective analyses ("reanalyses"), gridded temperature and precipitation station observations, and satellite information for solar radiation and rainfall (Ruane et al., 2013). In order to create a representative 30-year weather series for each location, neighboring sites from the highly spatially resolved WorldClim data, which is available historically as monthly values, were used. A total of 72 farm climate sites were used for Anantapur district (Fig 2).

Projections of future climate were obtained using CMIP5 and the Representative Concentration Pathways (RCP) for carbon emissions currently in use by the IPCC Fifth Assessment Report (IPCC 2014). Future climate projections were created using the "delta" method, in which the mean monthly changes (from baseline) for RCP 8.5 for Near, Mid and End Century time slices centered around 2030, 2055 and 2080, respectively, were applied to the daily baseline weather series. These monthly changes were imposed on baseline climate series for all selected sites by adding temperature changes to the baseline record and multiplying by a precipitation change factor. The 
156 future time scale weather series and the corresponding projected $\mathrm{CO}_{2}$ concentration, 157 according to RCP 8.5, were used in all crop model simulations. We refer to these future 158 projections as "mean change scenarios". This procedure was repeated for each of the 159 five global climate models (GCMs). The five GCMs used in this study are

160 a) CCSM4 : Community Climate System Model developed by University Corporation for Atmospheric Research, Boulder, CO, USA

b) GFDL-ESM2M- Geophysical Fluid Science Laboratory- Earth System Modeling developed by Princeton University, Princeton, NJ, USA

c) HadGEM2-ES: Hadley Centre Global Environment Model version 2. developed by Met Office Hadley Centre, UK

d) MIROC5: Model for Interdisciplinary Research on Climate, Japan

e) MPI-ESM-MR : Max-Planck-Institute Earth System Model running on medium resolution grid, Hamburg, Germany

\subsubsection{Soil Data}

Five different soil profiles of the soil orders were used (Fig 2). The farm locations were then mapped on the Anantapur soil map developed by the National Bureau of Soil Survey and Land Use Planning (NBSS\&LUP), Nagpur and the representative soil profile for each farm location point was prepared. Physical and chemical properties of the soil such as texture, hydraulic parameters, bulk density, organic matter and available $\mathrm{N}$ were estimated for each location based on the available soil profile data and expert knowledge. Additional soil parameters such as, soil albedo, drainage constant, and 
runoff curve number were estimated based on the soil texture data from the generic soil database available in the Decision Support System for Agrotechnology Transfer (DSSAT) -models (Tsuji et al., 1998).

\subsection{The CROPGRO-Peanut Model}

The CROPGRO-Peanut Model available in DSSAT v 4.5 simulates crop growth and development on daily time step. Soil water balance in the model is estimated based on Ritchie's water balance model (Ritchie, 1998). This is a one-dimensional model that computes daily changes in soil water content in a soil layer due to infiltration, irrigation, vertical drainage, unsaturated flow, soil evaporation, plant transpiration and root water uptake. Infiltration is calculated on the difference between rainfall (or irrigation) and runoff. Drainage is assumed to be constant throughout the whole day and computed for each layer using the drained upper limit and lower limit values of soil water content. When the water content in each layer is above the drained upper limit, water drains to the next layer. The amount of water passing to each layer is then compared to statured hydraulic conductivity (Ksat) of that layer. If the Ksat is less than the drainage then the actual drainage is limited to the Ksat value. The model uses the Priestly-Taylor method

to estimate daily potential evapotranspiration. It requires cultivar coefficients (cultivarspecific parameters) as an input to the model in addition to crop-specific coefficients that are considered less changeable or more conservative in nature across crop cultivars. The model can also simulate the impact of elevated temperatures on groundnut growth and development. High temperature influences growth and development and allocation of assimilates to the reproductive organs is reduced by decreased pod set and seed growth rate (Singh et al., 2014 ${ }^{\mathrm{b}}$ ). Similarly increased $\mathrm{CO}_{2}$ 
201 concentration in the atmosphere increases crop growth through increased leaf-level 202 photosynthesis, which responds to $\mathrm{CO}_{2}$ concentration using simplified RUBISCO 203 kinetics similar to Farquhar and von Caemmerer (1982).

\subsubsection{Model Calibration and Determination of Genetic Coefficients}

Model calibration involves the estimation of genotype coefficients to confirm an agreement between model predictions and observed values. The present model was calibrated for groundnut cultivar JL-24 with the data sets available with the International Crops Research Institute for the Semi-Arid-Tropics (ICRISAT) for the 1986-1991 seasons and multi-site Initial Variety Trials-II (IVT-II) data obtained from the Annual Reports of the All India Coordinated Research Project on Groundnut (Singh et al., 2012).

\subsubsection{Virtual cultivars}

Virtual cultivars that were developed by modifying various plant traits of JL-24 (Singh et al., $2014^{\text {b }}$ ) in addition to regular crop management decisions were used as one of the adaptation strategies. The main idea of testing drought and heat tolerant virtual cultivars in the study region was, the projected climate changes in this region will intensify the problems of heat and drought stress during critical periods of crop growth and hence we thought that cultivars having drought and heat tolerance will improve the groundnut yields. Different virtual cultivars included:

a) JL-24 with longer life cycle- To lengthen crop duration, the calibrated and evaluated genetic coefficients of JL-24 which determines $50 \%$ flowering (EM-FL), 
222 flowering to beginning seed growth (FL-SD) and beginning seed growth to physiological 223 maturity (SD-PM) were decreased by $10 \%$ each.

224 b) JL-24- with heat tolerance- In the groundnut species file the temperature 225 tolerance was increased by $2{ }^{\circ} \mathrm{C}$ for pod set, individual pod plus seed growth rate and 226 partitioning of assimilates to reproductive organs processes which are mainly influenced 227 by high temperatures.

228 c) JL-24 with drought tolerance- Changes were made in the relative root distribution 229 function (WR) and the lower limit of soil water availability (LL) for each soil layer 230 presuming that a drought tolerant cultivar has greater rooting density with depth in the 231 soil profile for greater access and mining of soil water, to enable extraction of water 232 more effectively from each given soil layer.

\section{2.3.3. Management decisions}

a) Supplemental irrigation

Supplemental irrigation is one of the management options studied which will be attractive to farmers and helps to address the financial risk associated with climate variability in groundnut. The current analysis simulated the impact of an irrigation application at 60 days after planting coinciding with the pod development stage.

\subsection{Decision support system architecture}

The decision support system linked with GIS receives spatial information on soil and weather from the built in data base, passes them to a process based crop simulation model for simulating crop growth and yield. The system enables spatial analysis of crop 
243 yield by running the crop simulation model for many locations. Location- wise inputs required for the crop model are generated from spatial layers of soil and weather data generated using highly spatially resolved WorldClim data. Figure 3 shows the broad framework of the decision support system with linkages between the GIS tools and crop simulation model and the architecture of the system. The system consists of four major components (a) inputs assimilates GIS system , (b) DSSAT crop simulation model (c) Querying system (d) Spatial output generating system.

250 Seventy two representative locations were selected in the study area, for which 251 soil and climate data and all other inputs required by the CROPGRO-Peanut model 252 were provided from the database developed. Simulations were carried out for each 253 location under current and future climate conditions using virtual cultivars and 254 management options. The modeled outputs at each point location were assimilated into 255 GIS. Using ordinary krigging interpolation, spatial yield maps were generated for the 256 Anantapur district to visualize the impact of climate change and various adaptation 257 strategies on groundnut yield. A simple visualization tool was developed using Dot Net 258 framework and Microsoft Structured Query Language (MS SQL) server as a data base 259 and hosted in a high- end server using the outputs generated from GIS. This tool 260 enables the user to spatially compare groundnut yields under different climate change 261 scenarios compared to the base period with and without adaptation options. The tool 262 can be accessed online (http://spatial-tools.icrisat.ac.in/). A desktop standalone 263 application was also developed to work offline. 


\subsubsection{Simulation of Crop Yields}

DSSAT's seasonal analysis option which allows multiple years run with the same 266 initial conditions was used to simulate the effects of climate variability on groundnut 267 yields for each of the 72 locations to study the impact of virtual cultivars and 268 management scenarios using historical baseline weather data (1980-2009). The aim 269 was to (a) to ascertain the most suitable management/cultivar options that resulted in 270 highest baseline yield and (b) understand how this combination might perform under 271 climate change conditions. Simulations were carried out for the baseline climate and the 272 projected climate change during Mid-century period for each site. The simulations were 273 initiated a month before sowing date each year and the soil profile was considered to be 274 at $50 \%$ available water on that day of sowing. Under normal sowing conditions the 275 sowing window was 1 July to 15 August and under delayed conditions the sowing for 276 Anantapur is from 15th July to 15th August. The simulated crop was sown on the day 277 cumulative rainfall in that particular window reached $50 \mathrm{~mm}$ in seven days. 278 Recommended nitrogen (20 kg/ha) was applied at the time of planting. A plant 279 population of 25 plants $\mathrm{m}^{2}$ with row spacing of $30 \mathrm{~cm}$ was considered for simulating 280 groundnut growth. Soil-limited photosynthesis factor (SLPF) of 0.74 was used for 281 Anantapur (Singh et al., 2014 ${ }^{\mathrm{b}}$ )

\section{3. Results of Decision Support System}

283 Seventy two location specific simulations were carried out in Anantapur district. 284 The soils in the study area mostly dominated by Alfisols and Aridisols followed by 
Inceptisols, Entisol and Vertisols. The soil carbon values ranged from 0.49 to $0.96 \%$ and the extractable water holding capacity of soil ranged from $90-165 \mathrm{~mm}$.

\section{3.1. Future Climate Characteristics Relative to Baseline} showed a 10.6 - 25\% increase during Mid-Century period (2040-69) with RCP 8.5 with MPI-ESM-MR showing the least and GFDL-ESM2M shows the highest increase in rainfall (Fig.4). The spatial distribution maps of rainfall also showed increased rainfall activity in northern and southern Anantapur district compared to the base line. Secondly, increase in September and October rainfall in all the GCMs studied was noted, which will have positive impact on crop growth and development (Fig 5). The spatial analysis of rainfall data reveals that increased rainfall activity will be observed in all the regions of Anantapur. The average increases in rainfall as predicted by five GCMs will be pronounced in the northern region (19\%) followed by the central region (17.4\%) southern region (16.8\%) and high level land (16.7\%),

Changes in mean crop season temperatures were predicted by five GCMs. Warming exceeding $1.4-2.4{ }^{\circ} \mathrm{C}$ by 2069 predicted in Anantapur district, with MIROC5 predicting more warming and HadGEM2-ES lesser warming. More warming will be observed in the eastern parts of the district. Spatial analysis of temperature changes indicated that almost uniform changes across all the regions. Minimum temperatures 
307 was more $\left(2.33-2.46{ }^{\circ} \mathrm{C}\right)$ than the maximum temperatures $\left(1.84-1.88{ }^{\circ} \mathrm{C}\right)$ in all the 308 regions of the district.

309 3.2. Base Yields

The base yields (1980-2009) in the study location ranged between $1057 \mathrm{~kg} / \mathrm{ha}$ 311 and $1659 \mathrm{~kg} / \mathrm{ha}$ showing spatial heterogeneity across the district. A spatial analysis of 312 yield data across the four natural divisions revealed highest yields in southern region 313 followed by highlands, central and northern regions. Under the current climate, 314 simulated groundnut yields vary by an order of annual rainfall amounts across the 315 locations and soil types. In general, the southern region with comparatively higher 316 rainfall, showed the highest crop yields. Pod yields were varied from $1199 \mathrm{~kg} \mathrm{ha}^{-1}$ in 317 Vertisols to $1509 \mathrm{~kg} \mathrm{ha}^{-1}$ in Alfisols. Different genetic traits in the form of virtual cultivars 318 and management options were simulated to quantify the impact of these technologies 319 on baseline groundnut yields. The yield benefit observed due to $10 \%$ longer maturity 320 cultivars was found to be very less (2\%). However, substantial spatial variability was 321 observed with in the district with southern region found to be benefited with $7 \%$ increase 322 and highland region with $2.6 \%$ increase in yields (Fig 6). Increasing the duration of the 323 baseline cultivar was not beneficial in the northern and central regions. Incorporating 324 drought tolerance traits in the base line cultivar showed an overall increase of $5 \%$ in 325 yields and a $4.5-5.8 \%$ increase in yields, across the regions. Among the agronomic 326 interventions simulated, providing one supplemental irrigation at 60 DAS showed 327 significant improvement in groundnut yields across location ranging from $12.6-21.5 \%$ 328 and an overall increase of $17 \%$. The northern region benefited the most with one 329 supplemental irrigation. The spatial maps on agronomic intervention of one 
supplemental irrigation generated for the district showed increased yields in almost all the places.

\subsection{Climate Change Impacts on Crop Yields}

Five GCMs were used to study the impact of climate change on groundnut yields under RCP 8.5 during Mid-century period. Table 1 shows the summary of the projected change (\%) in groundnut yields between the base line (1980-2009) and the Mid-century future climate (2040-69). Under climate change, groundnut yields declined in four of the

337 five GCMs tested. Only GFDL-ESM2M GCM showed positive impact on yields. Pod 338 yields decreased by $7.5 \%, 3.9 \%, 1.2 \%$, and $0.2 \%$ with MIROC5, CCSM 4, MPI-ESM339 MR, and HadGEM2-ES respectively. GFDL-ESM2M GCM predicted a $6.1 \%$ increase in 340 groundnut yields. The spatial analysis of climate change impacts on groundnut indicates 341 that similar trends were observed in almost all the regions of Anantapur with a decline in 342 yields with four GCMs and increase with one GCM (Fig 7). However, while the northern 343 region was found to be greatly benefited with climate change as predicted by GFDL344 ESM2M and HadGEM2-ES, the southern region was found to be more vulnerable to it. 345 The spatial maps of impacts of climate change also depict similar results for groundnut 346 in Anantapur district.

\section{3.4. Adaptation Strategies}

348 As an adaptation strategy to combat climate change impacts on groundnut, 349 Virtual cultivars by incorporating various desirable plant traits and agronomic 350 management options were tried as an adaptation strategy. Virtual cultivar having heat, 
351 drought and 10\% longer life cycle, management option such as supplemental irrigation at 60 DAS were simulated to study spatial variations in groundnut yields.

\subsubsection{Cultivars with $10 \%$ Longer Life Cycle}

354 Simulations with longer life cycle cultivar under climate change conditions 355 resulted in an overall positive response with an average $1.8 \%$ increase in yields across 356 locations. However, this was more prevalent in the southern region where there was a $3576.8 \%$ increase in groundnut yields while it was $2.1 \%$ in the highlands region compared 358 to the base line cultivar yields under climate change. This adaptation strategy was not 359 beneficial in the central and northern regions as it resulted in a 0.4 and $-0.8 \%$ reduction 360 in groundnut yields respectively

\section{3.4.2. Drought Tolerance} southern region showed negative impact.

Incorporating drought tolerance traits into base cultivar resulted in significant yield improvements across locations in Anantapur. Yield increases ranged from 4.5 $6.0 \%$ with highland, central and northern region found to benefited most compared to southern region (Fig 8).

\subsubsection{Heat tolerance cultivar}

Incorporating heat tolerance traits into baseline cultivar resulted in a meagre increase in groundnut yields in Anantapur, ranging from $0.8 \%-1.9 \%$. The northern, central and highland regions showed positive response for heat tolerance and the 


\subsubsection{Supplemental irrigation}

373 Supplemental irrigation was found to be one of the best agronomic adaptation 374 strategies to increase groundnut yields significantly under climate change conditions. In 375 all the five GCMs and regions tested the application of one irrigation at 60 DAS 376 increased groundnut yield to the tune of $14.4 \%$ compared to the normal practice. A 377 single supplemental irrigation was more beneficial in the northern and central region 378 with $16.8 \%$ and $15.9 \%$ improvement, respectively compared to that in the highland $379(13.7 \%)$ and southern regions (11.3\%). The spatial maps generated on the impact of 380 one supplemental irrigation on groundnut yields under climate change conditions as 381 simulated with five GCMs showed increased yields at almost all the locations in 382 Anantapur districts (Fig 9).

383 Among the combination of adaptation options studied, a combination of drought 384 tolerance traits and supplemental irrigation were found to be very effective in improving 385 groundnut yields by $20 \%$ under climate change conditions compared to base line 386 cultivar under climate change. The northern and central regions benefited highly by this 387 adaptation strategy leading to $23.6 \%$ and $21.9 \%$ increases respectively in yields 388 followed by the highland and southern regions with 19.3 and $16.1 \%$ increases 389 respectively.

390 4. Discussion

391 The present study attempted to develop a user-friendly decision support tool to 392 quantify the potential impacts of future climate change on groundnut yields. The tool will 393 provide useful insights essential to inform policies, prioritize research, reform crop 
management practices, and adjust the distribution of various adaptation options to reduce vulnerability in the future. The overall results clearly show the capabilities of CROPGRO-Peanut model to simulate groundnut yields under varying soil, climate and management conditions enabling us to simulate and analyze the impact of climate change and various adaptation options to mitigate its impacts. Despite considerable uncertainty relating to future climate change and its consequences (Challinor 2011), this analysis is probably the first study that considers the impact of climate change analysis using farm climate data in four different regions using six different soil types. Significant variation in the baseline yields can be attributed due to soils and rainfall. Regression analysis indicates that rainfall positively and significantly affects groundnut yields. Among different soils, Alfisols have highly positive and significant impact on crop yields. These simulation results confirm the earlier studies of Alfisols being best suited for groundnut cultivation and that rainfall is an important factor which controls yields in Anantapur (Bapuji Rao et al 2011). Analysis of five GCMs demonstrated that there is considerable increase in rainfall activity in the range of 10.6 to $25 \%$ by Mid-century period (2040-69) under RCP 8.5. Among the various regions studied, greater activity was observed in the northern region which resulted in a marginal increase in groundnut yields even under increased maximum and minimum temperatures. Further analysis of rainfall distribution indicated an increase in rainfall in September and October in almost all GCMs. However, there was slight decrease in rainfall in November which coincided with pod filling and led to a slight decrease in pod yields. The variation in crop yields among the different locations is mainly because of variations in the soil type, rainfall and temperatures which affect various daily biochemical processes in the plant. The main 
417 reason for reduced yields in the simulations during Mid-century period was to the effect 418 of higher temperature leading to an acceleration of the phenological cycle and finally 419 reduction in yields. A large variation was found across soil types under both current and future climate conditions, implying groundnut sensitivity to soil types.

\subsection{Determination of Adaptation Options}

The impacts of climate change on groundnut can be quantified effectively using simulation modeling studies; we can also study the extent to which the impacts can be avoided through various adaptation options. Different management scenarios were studied using baseline climate data, shifting planting dates in order to prevent the critical stages of crop development coinciding with the extreme high-temperature period. However, this didn't result in improved yields as delayed sowing led to crop exposure to moisture stress during the critical pod filling stage. Other agronomic options such as critical irrigation have proved highly beneficial as the model simulations of rainfed groundnut indicates that the crop experienced water stress during pod filling stage and providing one irrigation during pod filling stage was found to increase yields in almost all the regions both under baseline and future climate situations.

Incorporating various promising traits such as drought and heat tolerance and a longer life cycle in groundnut was found beneficial in improving groundnut yields under climate change conditions. Groundnut requires an optimum temperature range of 25-30 ${ }^{\circ} \mathrm{C}$ for vegetative development (Williams and Boote, 1995; Weiss, 2000) and $35{ }^{\circ} \mathrm{C}$ for flower appearance and pegging (Prasad et al 2003). As per future climate projections, daily temperatures may exceed optimum temperature and even some times record more than critical temperatures during the groundnut growing period, inhibiting crop 
440 development and productivity. High temperatures delay pegging and podding and lead 441 to reduction in yield. Thus developing virtual cultivars with high temperature tolerance

442 and high thermal requirements may lead to their effective use of the growing season to

\section{Conclusions}

This study developed and tested a tool for investigating the spatial implications of climate change on groundnut production in Anantapur district. The CROPGRO-Peanut model that has been calibrated and validated for many groundnut growing regions of the 
464 world was used to study the spatial responses to various genetic and agronomic 465 management practices under both baseline and climate change scenarios by using GIS and crop model based interface. The methodology presented here was found to be reassuring because it provides a common ground for breeders, plant physiologist, crop modelers and GIS users to discuss simulation results and further potential research directions. Simulated crop yield and other maps generated under different management scenarios can be used to better communicate model predictions to various stakeholders. Further, the methodology developed can be used for spatial modeling of crop productivity for any crop in any region or country. The output of this methodology 473 can aid scientists in prioritizing research and decision makers to understand the extent 474 and status of climate change and its potential impacts on the productivity of various 475 crops.

477 Acknowledgements

478 This work was supported in part by the CGIAR Research Program on Policies, 479 Institutions and Markets, The Global Futures Project funded by the Bill \& Melinda Gates 480 Foundation, and the CGIAR Research Program on Climate Change, Agricultural and 481 Food Security (CCAFS) and the CGIAR Research Program on Grain Legumes 


\section{Figure captions}

483 Fig 1. Location of the study area in- Anantapur district, Andhra Pradesh, India

484 Fig 2. Map showing the Soils (source: NBSS\&LUP, Nagpur), weather station and farm climate locations

485 Fig 3. Basic architecture of the decision support system

486 Fig 4. GCM projected change in crop season rainfall $(\mathrm{mm})$ during mid-century period compared to the 487 baseline in Anantapur. Bars indicate the standard error

488 Fig 5. Box-plots of five GCMs projected changes in monthly rainfall $(\mathrm{mm})$ during mid-century period at 489 four natural divisions of Anantapur

490 Fig 6. Effect of heat, drought tolerant virtual cultivars and management options on groundnut yields $491(\mathrm{~kg} / \mathrm{ha})$ in Anantapur as projected by five GCMs compared to baseline. Bars indicate the standard error

492 Fig 7. Spatial distribution of groundnut yields as projected by five GCMs for mid-century period under 493 RCP 8.5 compared to the baseline

494 Fig 8. Spatial distribution of groundnut yields as projected by five GCMs for mid-century period under 495 RCP 8.5 compared to the baseline having drought tolerance trait

496 Fig 9. Spatial distribution of groundnut yields as projected by five GCMs for mid-century period under 497 RCP 8.5 compared to the baseline receiving supplemental irrigation at 60 DAS 


\section{References}

Bapuji Rao, B., Ramana Rao, B.V., Subba Rao, A.V.M., Manikandan, N., Narasimha Rao, S.B.S., Rao, V.U.M. and Venkateswarlu, B. Assessment of the impact of increasing temperature and rainfall variability on crop productivity in drylands - An illustrative approach. Research Bulletin 1/2011, Central Research Institute for Dryland Agriculture, Santoshnagar, Hyderabad, Andhra Pradesh, India. 2011: 32p.

Behera SK, Panda RK. Integrated management of irrigation water and fertilizers for wheat crop using field experiments and simulation modeling. Agric Water Manage 2009; 96: 1532-1540.

Bulatewicz T, Jin W, Staggenborg S, Lauwo S, Miller M, Das S, Andresen D, Peterson J, Steward DR, Welch SM.. Calibration of a crop model to irrigated water use using a genetic algorithm. Hydrol Earth Syst Sci 2009; 13: 1467-1483.

Challinor A. Agriculture: Forecasting food. Nat Climate Change 2011; 1:103-104.

Chaturvedi RK, Joshi J, Jayaraman M, Bala G, Ravindranath NH. Multi-model climate change projections for India under representative concentration pathways. Current Sci 2012; 103: 791-802

Clifford, SC, Stronach IM, Mohamed AD, Azam-Ali SN, Crout, NMJ. The effects of elevated atmospheric carbon dioxide and water stress on light interception, dry matter production and yield in stands of groundnut (Arachis hypogaea L.). J. Exp. Bot. 1993; 44; 1763-1770.

Farquhar GD, von Caemmerer S. Modeling of photosynthetic response to environment. In: O. L. Lange, P. S. Nobel, C. B. Osmond and H. Zeigler, eds. Encyclopedia of Plant Physiology. Physiological plant ecology II. Springer-Verlag, Berlin. 1982. New series. Vol. 12B: 549-587.

Fortes PS, Platonov AE, Pereira LS. GISAREG-A GIS based irrigation scheduling simulation model to support improved water use. Agric Water Manage 2005; 77: 159-179.

Godfray HCJ, Beddington JR, Crute IR, Haddad L, Lawrence D, Muir JF, Pretty J, Robinson S, Thomas SM, Toulmin C. Food security: the challenge of feeding 9 billion people. Science 2010, 327(5967):812-818.

Howden SM, Soussana JF, Tubiello FN, Chhetri N, Dunlop M, Meinke H. Adapting agriculture to climate change. Proc Natl Acad Sci USA 2007, 104(50):1969119696. 
IPCC. Climate change 2007: impacts, adaptation and vulnerability. In: Parry, ML, Canziani, OF, Palutikof, JP, van der Linden, PJ, Hanson, CE. editors. Contribution of working group I to the fourth assessment report of the intergovernmental panel on climate change. Cambridge, United Kingdom and New York, NY, USA: Cambridge University Press; 2007. (273-313 pp.).

IPCC. Climate Change 2014: Impacts, Adaptation, and Vulnerability. Part B: Regional Aspects. In: Barros, VR, Field CB, Dokken DJ, Mastrandrea MD, Mach KJ, Bilir TJ, Chatterjee M, Ebi KL, Estrada YO, Genova RC, Girma, B, Kissel ES, Levy, AN, MacCracken S, Mastrandrea PR, White LL, editors. Contribution of Working Group II to the Fifth Assessment Report of the Intergovernmental Panel on Climate Change Cambridge University Press, Cambridge, United Kingdom and New York, NY, USA, 2014 (688 pp.).

Jagtap SS, Jones JW. Adaptation and evaluation of the CROPGRO-soybean model to predict regional yield and production. Agric Ecosyst Environ 2002; 93: 73-85.

Jagtap SS, Jones JW. Adaptation and evaluation of the CROPGRO-soybean model to predict regional yield and production. Agric Ecosyst Environ 2002; 93: 73-85.

Knox J, Hess T, Daccache A,Wheeler T. Climate change impacts on crop productivity in Africa and South Asia. Environ. Res. Lett. 7034032 IOPscience

Krishnan P, Swain DK, Chandra Bhaskar B, Nayak SK, Dash RN. Impact of elevated $\mathrm{CO} 2$ and temperature on rice yield and methods of adaptation as evaluated by crop simulation studies. Agric Ecosyst Environ 2007; 122:233-42.

Liu HL, Yang JY, Drury CF, Reynolds WD, Tan CS, Bai YL, He P, Jin J, Hoogenboom G. Using the DSSAT-CERES-Maize model to simulate crop yield and nitrogen cycling in fields under long-term continuous maize production. Nutr Cycling Agroecosyst 2011; 89: 313-328.

Lobell DB, Burke MB, Tebaldi C, Mastrandrea MD, Falcon WP, Naylor RL: Prioritizing climate change adaptation needs for food security in 2030. Science 2008, 319(5863):607-610.

Mishra A, Singh R, Raghuwanshi NS, Chatterjee C, Froebrich J. Spatial variability of climate change impacts on yield of rice and wheat in the Indian Ganga Basin. Sci Total Environ 2013; 468-469:S132-S138.

Müller C, Cramer W, Hare WL, Lotze-Campen H. Climate change risks for African agriculture Proc Natl Acad Sci 2011; 108: 4313-5

Naresh Kumar S, Aggarwal PK, Saxena R, Rani S, Jain S, Chauhan N. An assessment of regional vulnerability of rice to climate change in India. Clim Change 2013; 3-4: 683-699. 
Prasad PVV, Boote K J, Allen LH Jr., Thomas JMG. Super-optimal temperatures are detrimental to peanut (Arachis hypogaea L.) reproductive processes and yield at both ambient and elevated carbon dioxide. Glob Chang Biol 2003; 9: 1775-1787

Reidsma P, Ewert F, Oude Lansink A, Leemans R. Adaptation to climate change and cli- mate variability in European agriculture: the importance of farm level responses. Eur J Agron 2010; 32:91-102.

Rinaldi M. Water availability at planting and nitrogen management of durum wheat: a seasonal analysis with the CERES- Wheat model. Field Crops Res. 2004; 89: 27 37.

Rinaldi M, Ventrella D, Gagliano C. Comparison of nitrogen and irrigation strategies in tomato using CROPGRO model. A case study from Southern Italy. Agric Water Manage 2007; 87: 91-105.

Ritchie JT. Soil water balance and plant stress. In: Understanding options for agricultural production. Eds. G.Y Tsuji, G. Hoogenboom and P.K. Thornton. Kluwer Academic Publishers, Dordrecht, the Netherlands. 1998. p: 41-54.

Roudier P, Sultan B, Quirion P, Berg A. The impact of future climate change on West African crop yields: what does the recent literature say? Glob Environ Change $2011 ; 21: 1073-83$.

Ruane AC, Goldberg R, Chryssanthacopoulos J. AgMIP climate forcing datasets for agricultural modeling: Merged products for gap-filling and historical climate series estimation. Agric For Meteorol 2014; in press

Singh P, Boote KJ, Kumar U, Srinivas K, Nigam S N, Jones, JW. Evaluation of genetic traits for improving productivity and adaptation of groundnut to climate change in India. J Agro Crop Sci 2012; 1-15.

Singh P, Nedumaran S, Boote KJ, Gaur PM, Srinivas K, and Bantilan MCS. Climate change impacts and potential benefits of drought and heat tolerance in chickpea in South Asia and East Africa. Eur J of Agron 2014; ; 52: 123-137.

Singh P, Nedumaran S, Ntare BR and Boote, KJ, Singh NP, Srinivas K, and Bantilan MCS. Potential benefits of drought and heat tolerance in groundnut for adaptation to climate change in India and West Africa. Mitig Adapt Strateg Glob Change. $2014^{\mathrm{b}}: 19: 509-529$.

Thornton PK, Jones PG, Alagarswamy G, Andresen J. Spatial variation of crop yield response to climate change in East Africa. Glob Environ Change: Human Policy $\operatorname{Dim} 2009,19(1): 54-65$.

Tsuji GY, Hoogenboom G, Thornton PK. Understanding options for agricultural production. Systems approaches for sustainable agricultural development. Kluwer Academic Publishers, Dordrecht, the Netherlands.1998. 
You L, Rosegrant MW, Wooda S, Sun D. Impact of growing season temperature on wheat productivity in China. Agric For Meteorol 2009;149:1009-14.

Walthall CL, Hatfield J Backlund P, Lengnick, $L$ et al. Climate Change and Agriculture in the United States: Effects and Adaptation. USDA Technical Bulletin 1935. Washington, DC; 2012. p 1-186.

Weiss E. A. (2000). Oilseed Crops. Blackwell Science, London.

Williams $\mathrm{JH}$, Boote KJ. Physiology and modelling-Predicting the unpredictable legume. In: Advances in Peanut Science (H. E. Pattee and H. T. Stalker, Eds.), pp. 301335. APRES, Stillwater, Oklahoma 
Table 1. The summary of climate change impacts on groundnut in four regions of Anantapur during mid-century period

\begin{tabular}{|c|c|c|c|c|c|c|c|c|c|c|c|c|c|}
\hline \multirow{3}{*}{ Region } & \multirow{3}{*}{$\begin{array}{l}\text { Base } \\
\text { climate } \\
(1980- \\
\text { 2009) } \\
\text { Yield }\end{array}$} & \multicolumn{12}{|c|}{ Climate change (2040-2069) } \\
\hline & & \multicolumn{2}{|c|}{ CCSM4 } & \multicolumn{2}{|c|}{ GFDL-ESM2M } & \multicolumn{2}{|c|}{ HadGEM2-ES } & \multicolumn{2}{|c|}{ MIROC5 } & \multicolumn{2}{|c|}{ MPI-ESM-MR } & \multicolumn{2}{|c|}{$\begin{array}{l}\text { Average of } 5 \\
\text { GCMs }\end{array}$} \\
\hline & & Yield & $\begin{array}{l}\% \\
\text { change }\end{array}$ & Yield & $\begin{array}{l}\% \\
\text { change }\end{array}$ & Yield & $\begin{array}{l}\% \\
\text { change }\end{array}$ & Yield & $\begin{array}{l}\% \\
\text { change }\end{array}$ & Yield & $\begin{array}{l}\% \\
\text { change }\end{array}$ & Yield & $\begin{array}{l}\% \\
\text { change }\end{array}$ \\
\hline Northern region & 1264 & 1250 & -1.1 & 1429 & 13.0 & 1318 & 4.2 & 1163 & -8.0 & 1277 & 1.0 & 1287 & 1.8 \\
\hline Central region & 1317 & 1253 & -4.8 & 1408 & 6.9 & 1305 & -0.9 & 1212 & -8.0 & 1295 & -1.6 & 1295 & -1.7 \\
\hline High land region & 1380 & 1290 & -6.5 & 1451 & 5.1 & 1362 & -1.3 & 1278 & -7.4 & 1374 & -0.4 & 1351 & -2.1 \\
\hline Southern region & 1565 & 1524 & -2.6 & 1573 & 0.5 & 1532 & -2.1 & 1465 & -6.4 & 1520 & -2.9 & 1523 & -2.7 \\
\hline Anantapur district & 1381 & 1329 & -3.8 & 1465 & 6.1 & 1379 & -0.2 & 1279 & -7.4 & 1366 & -1.1 & 1364 & -1.3 \\
\hline
\end{tabular}




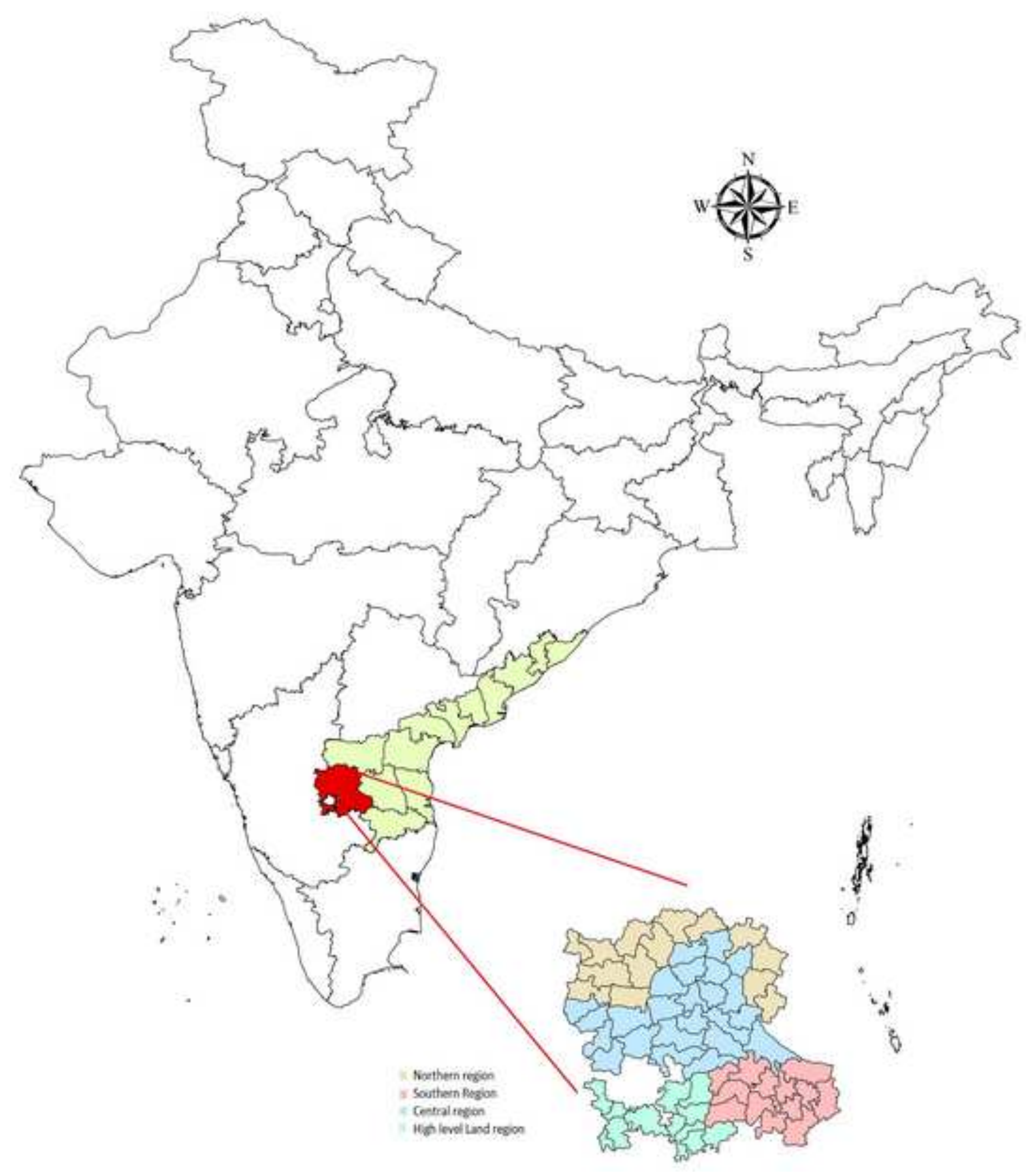

Figure 


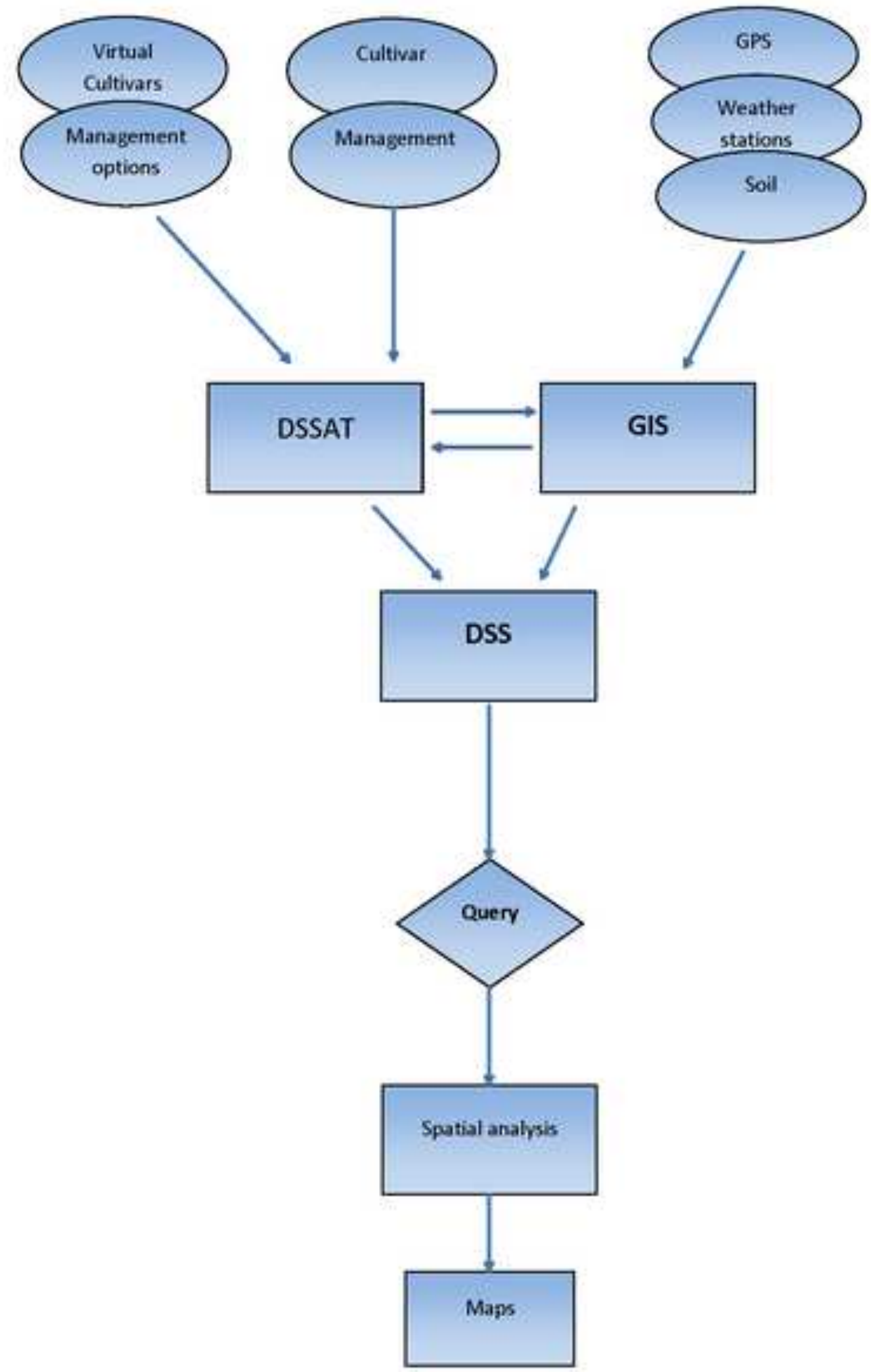




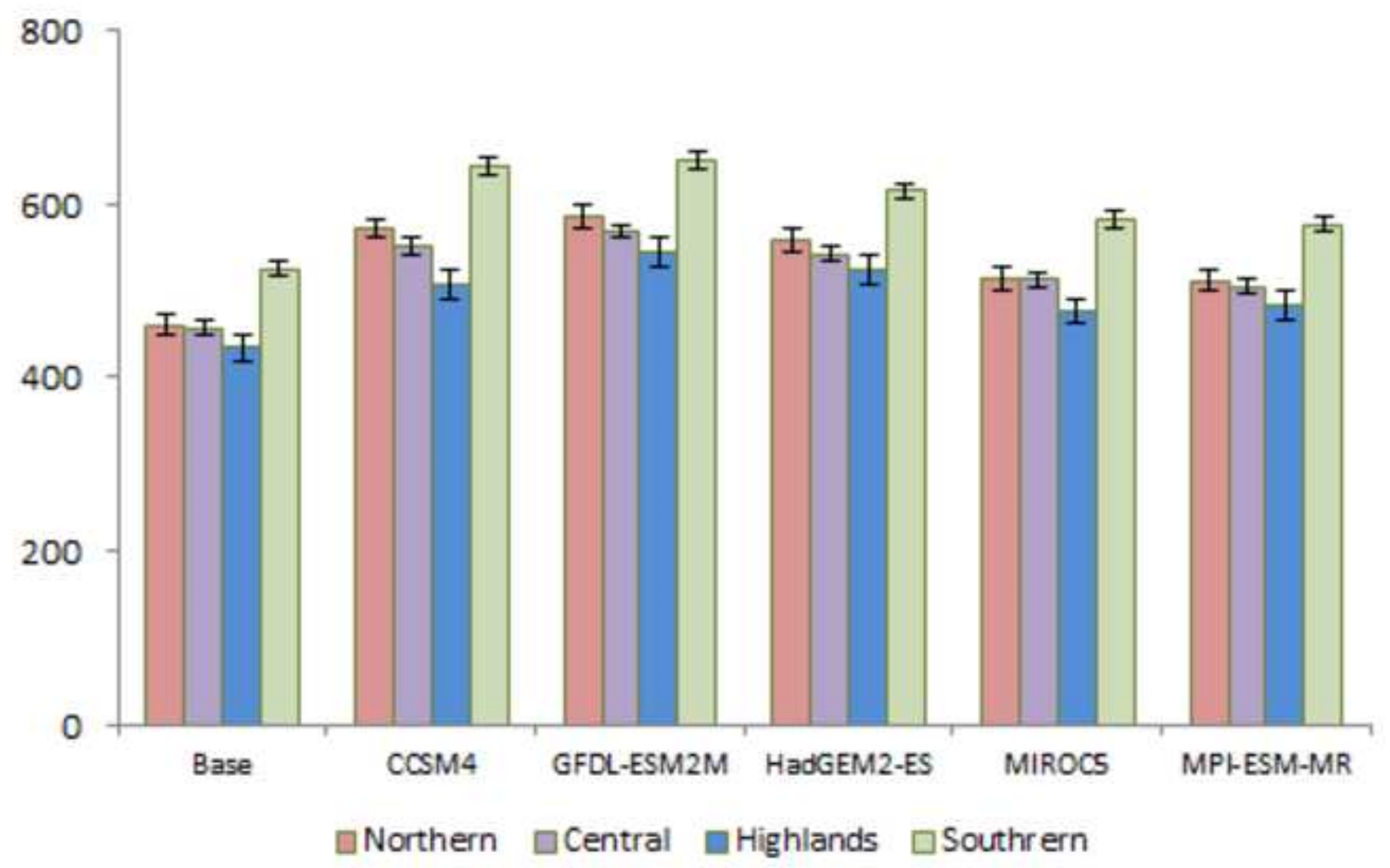

$\square$ Northern $\square$ Central $\square$ Highlands $\square$ Southrern 


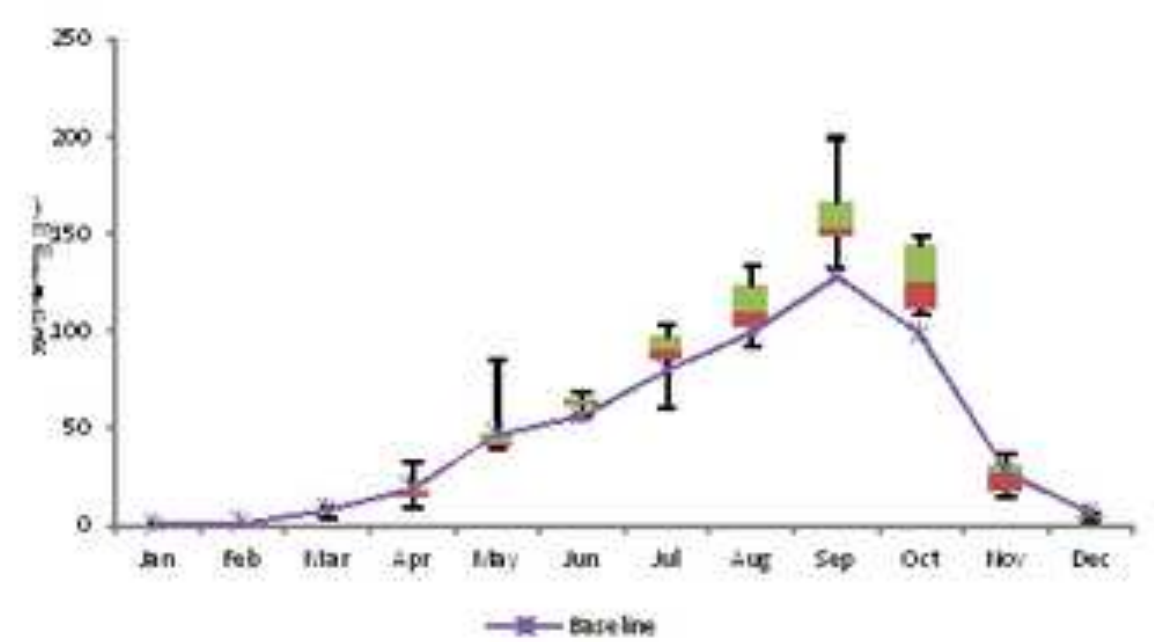

a) Northern Region

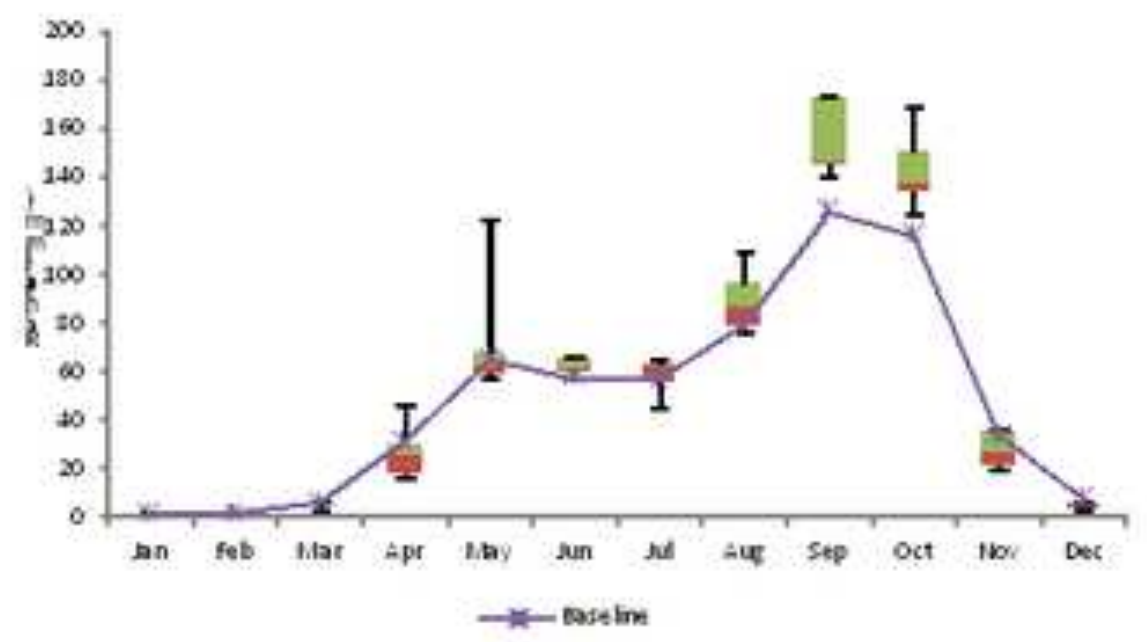

c) High land region

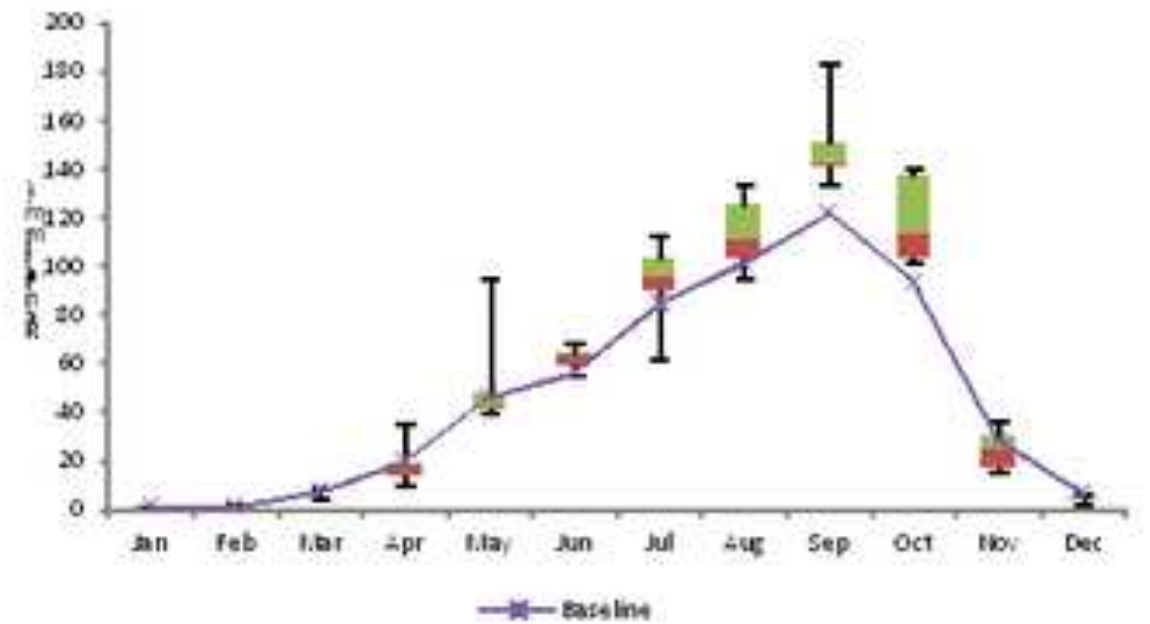

b) Central region

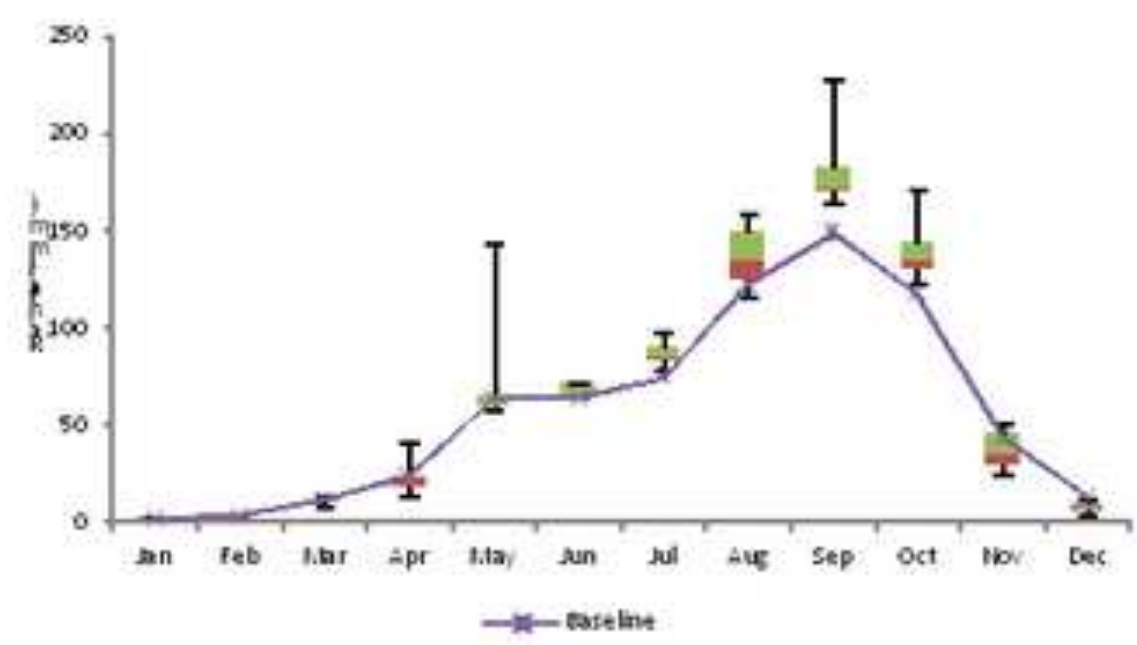

d) Southern region 


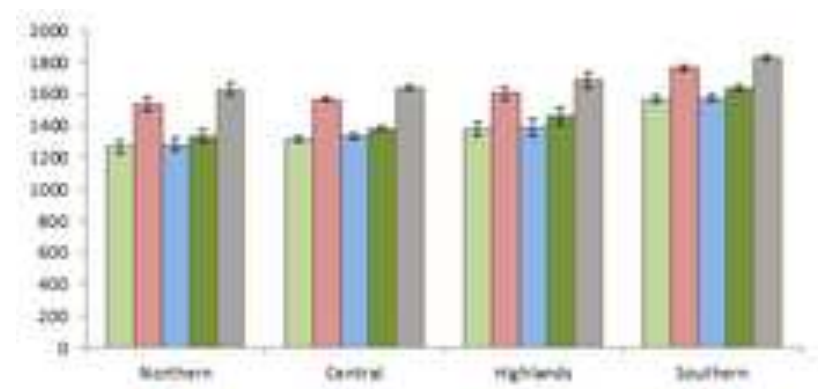

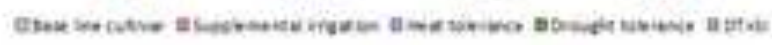
Gane cilimate

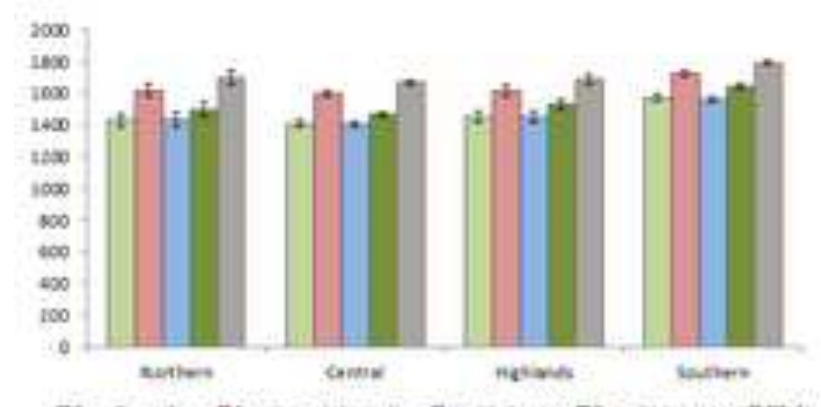

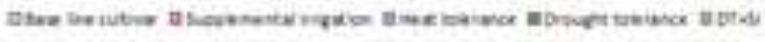
grousensu

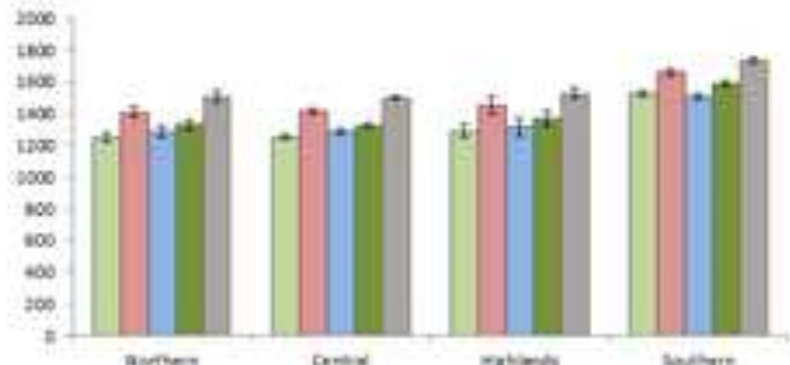

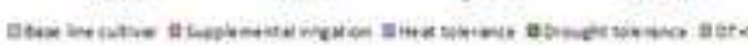

ccsan

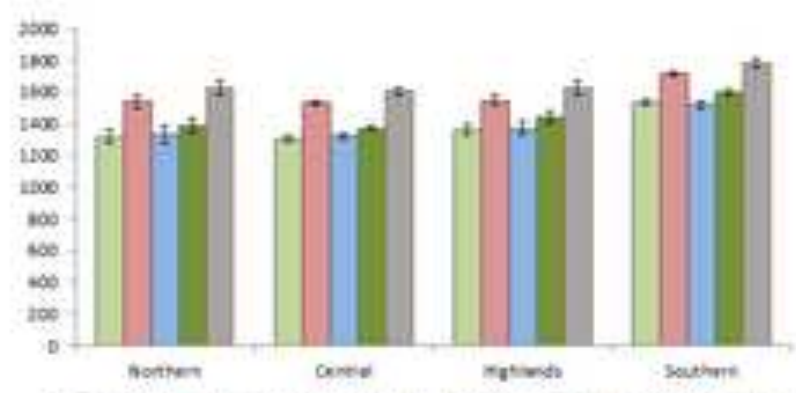

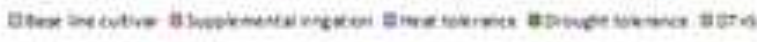
Hacceuses

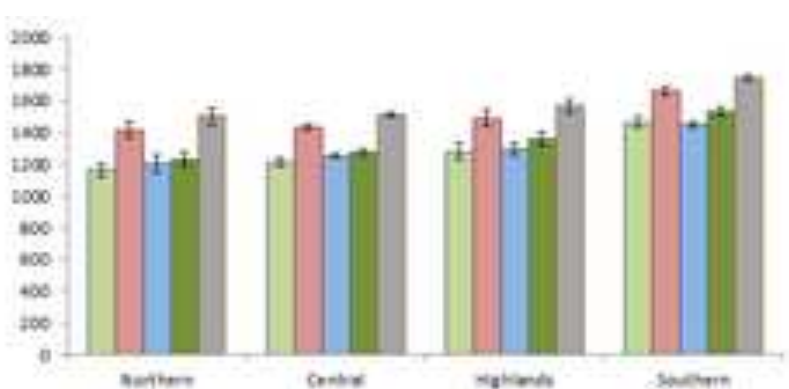

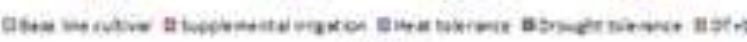
inpocs

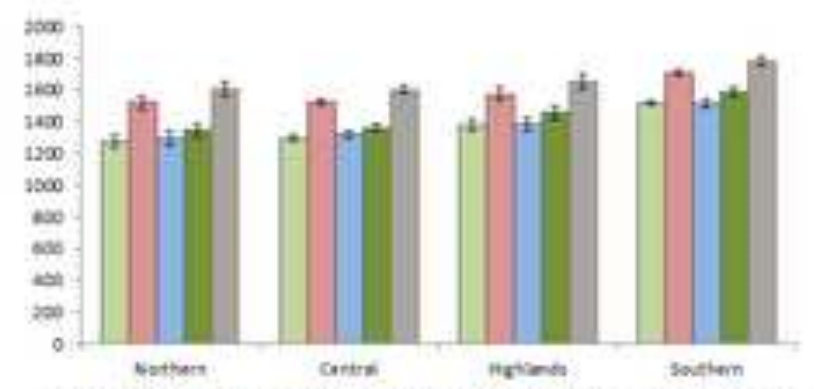

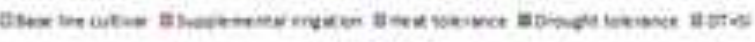
upesami 


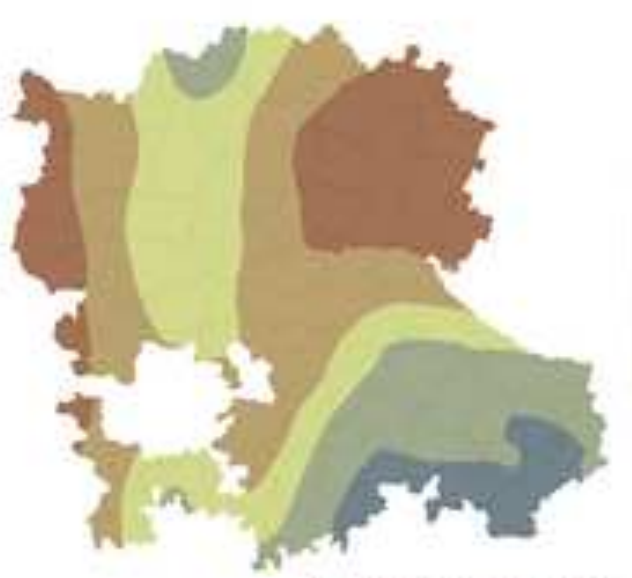

b) $\cos M 4$

e) MIROC5

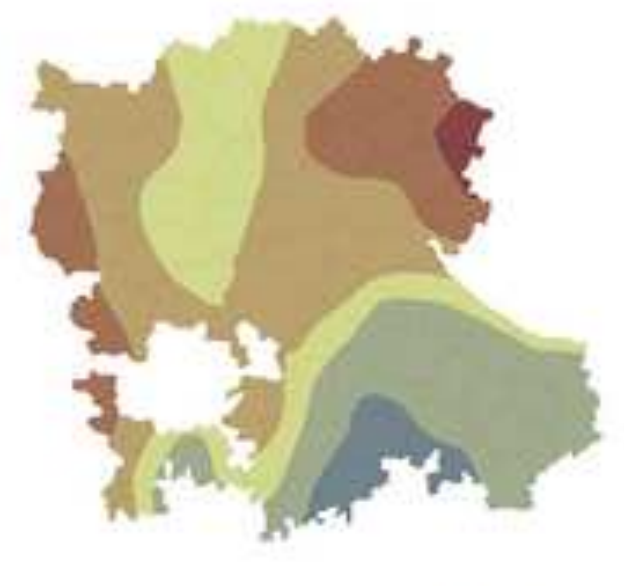

Figure

Figure
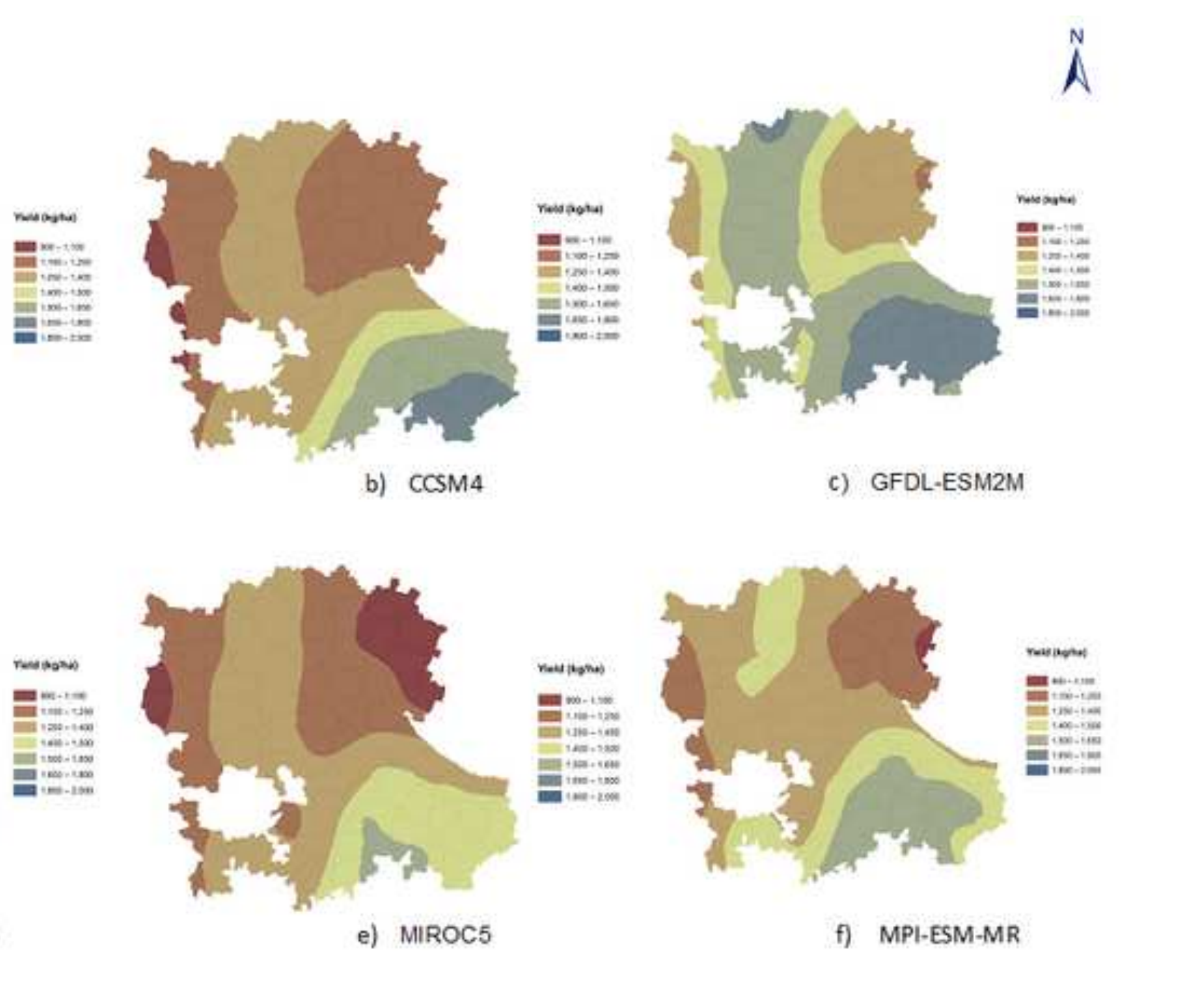

nolesate.

믈

불.

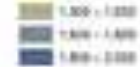

c) GFDL-ESM2M

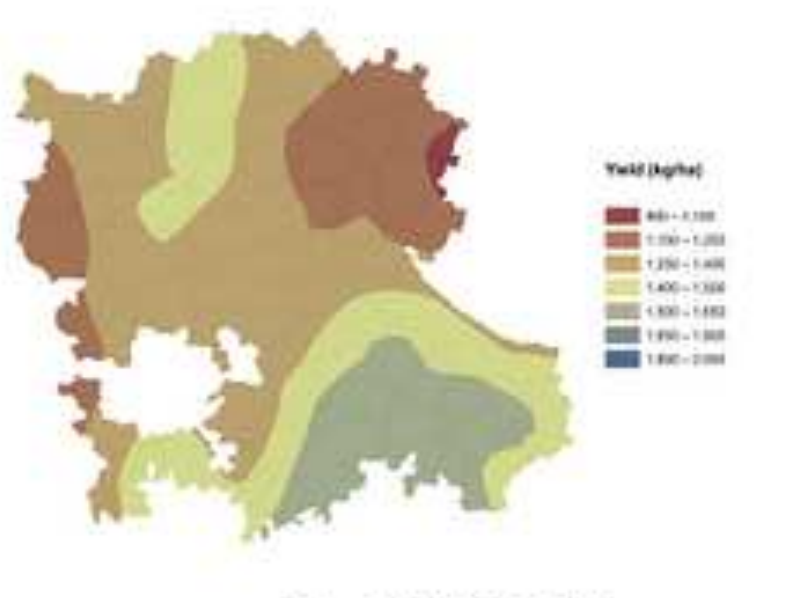

f) MPI-ESM-MR
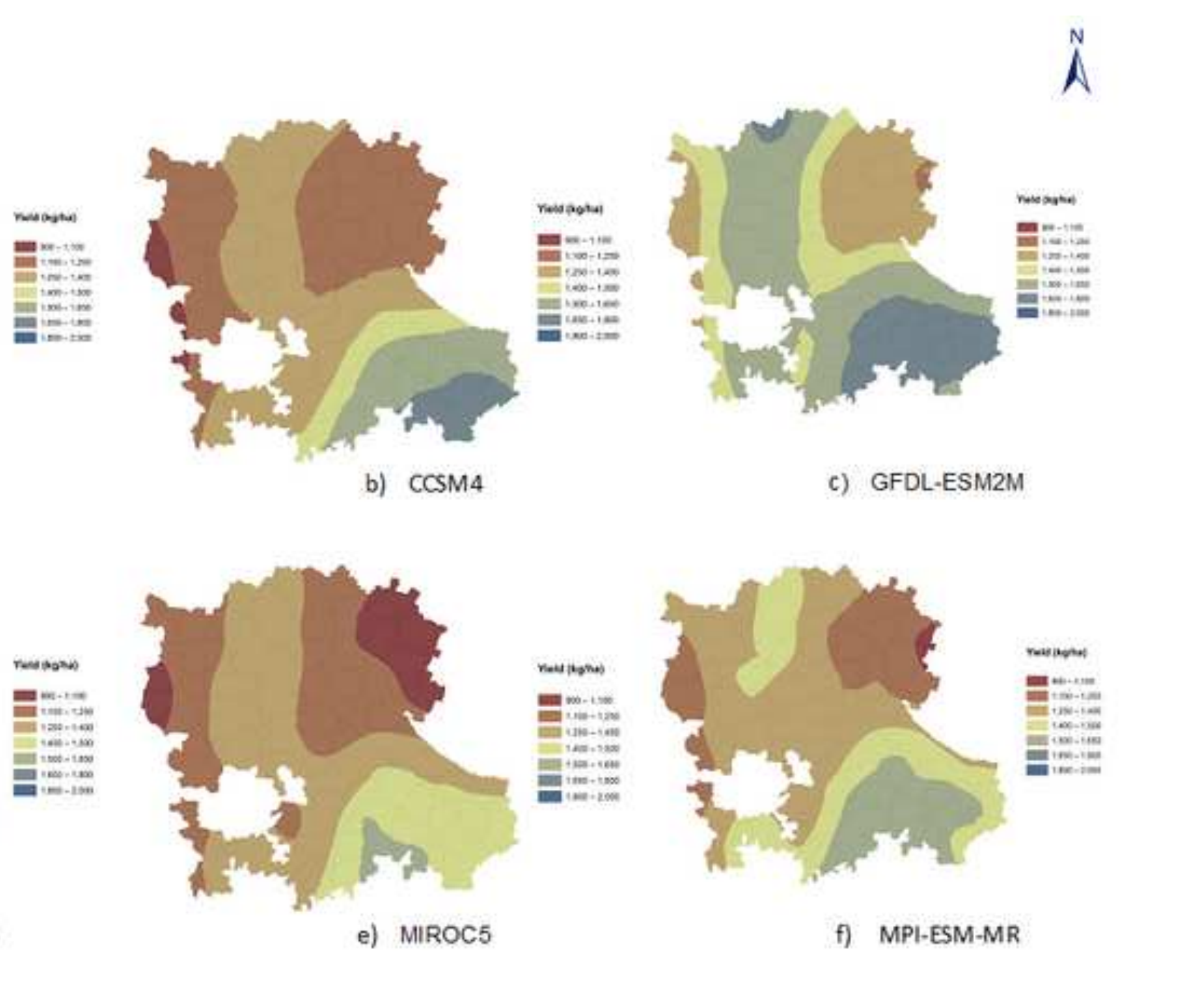
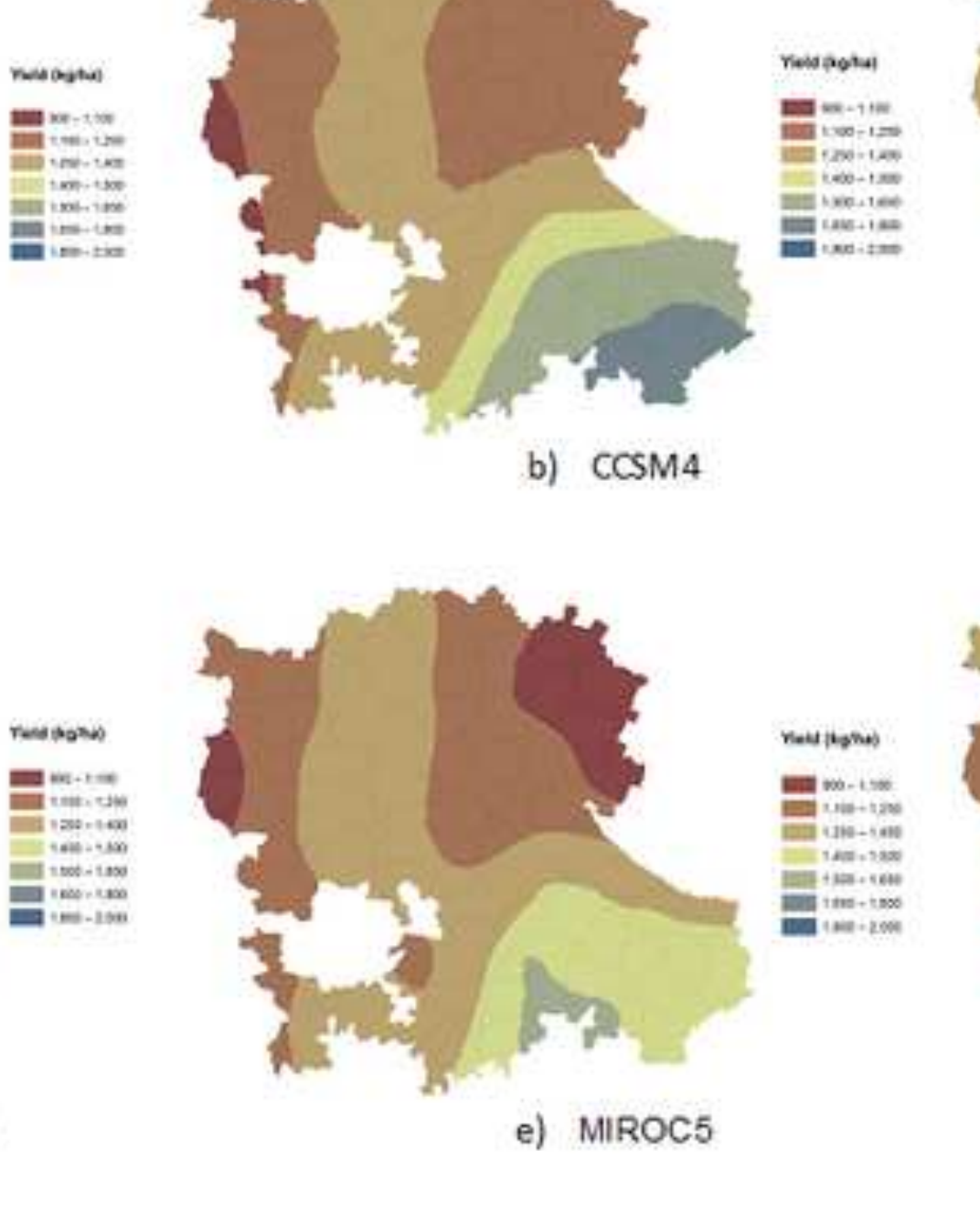

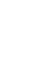

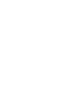

要

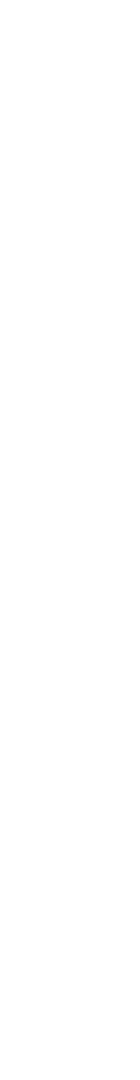

.

.
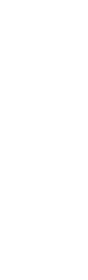


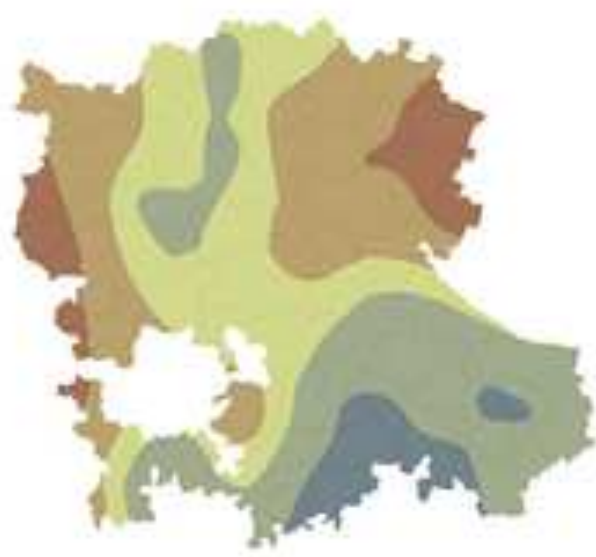

a) Base Line

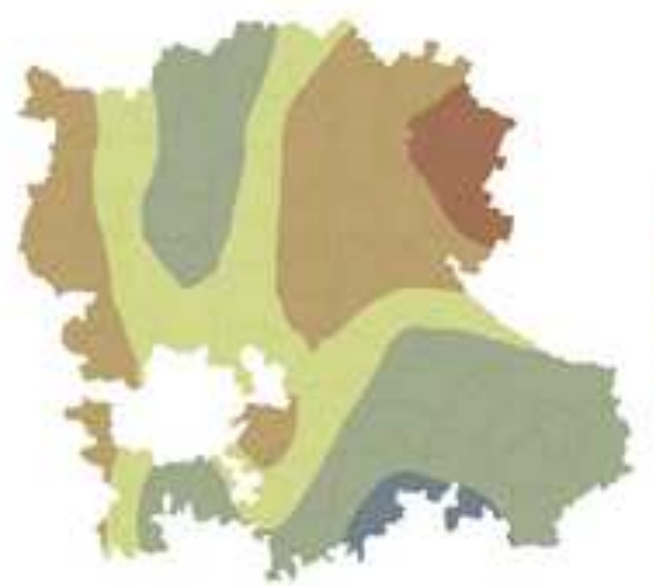

d) HadGEM2-ES

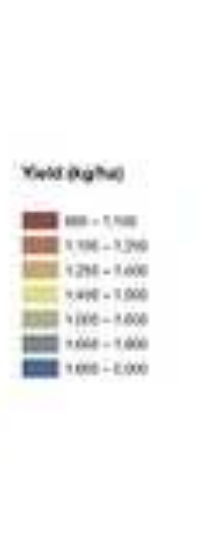

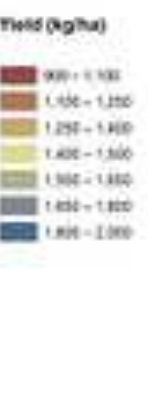

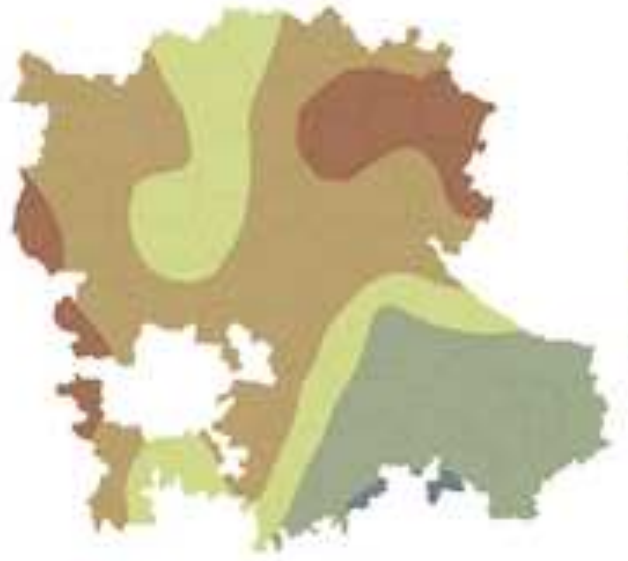

b) $\cos M 4$

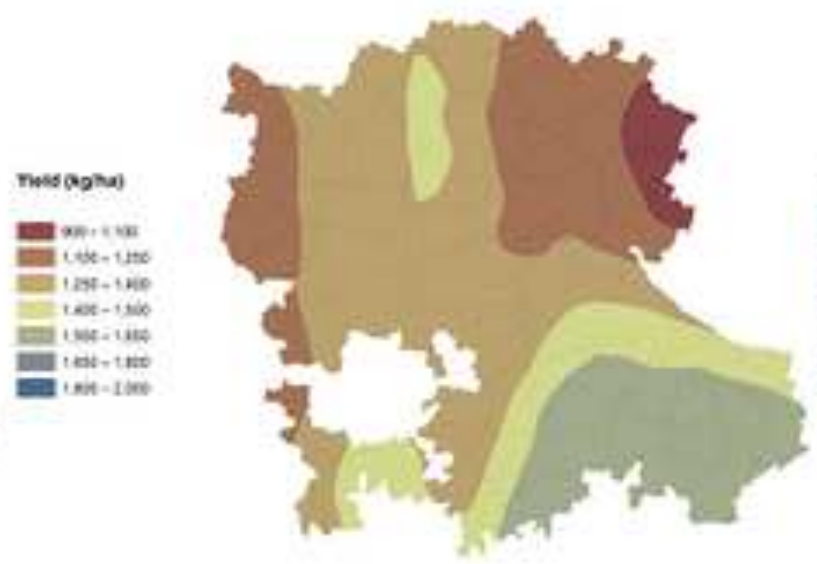

e) MIROC5
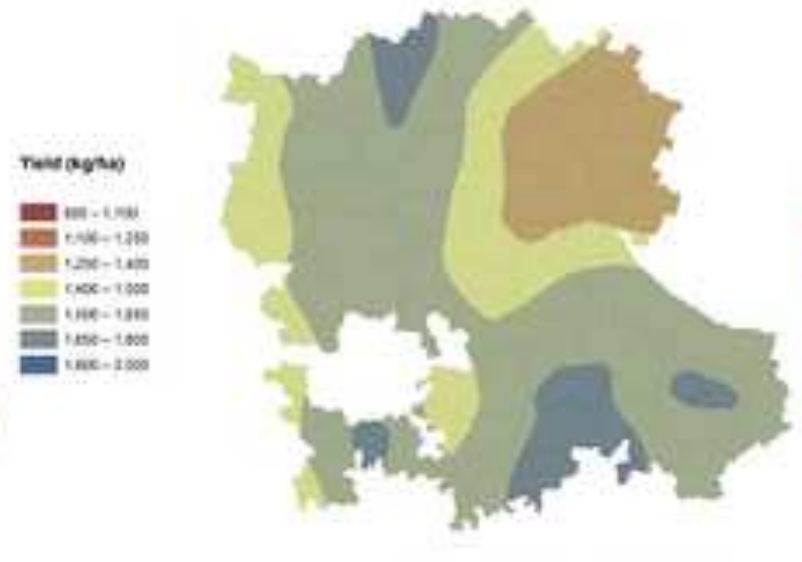

c) GFDL-ESM2M

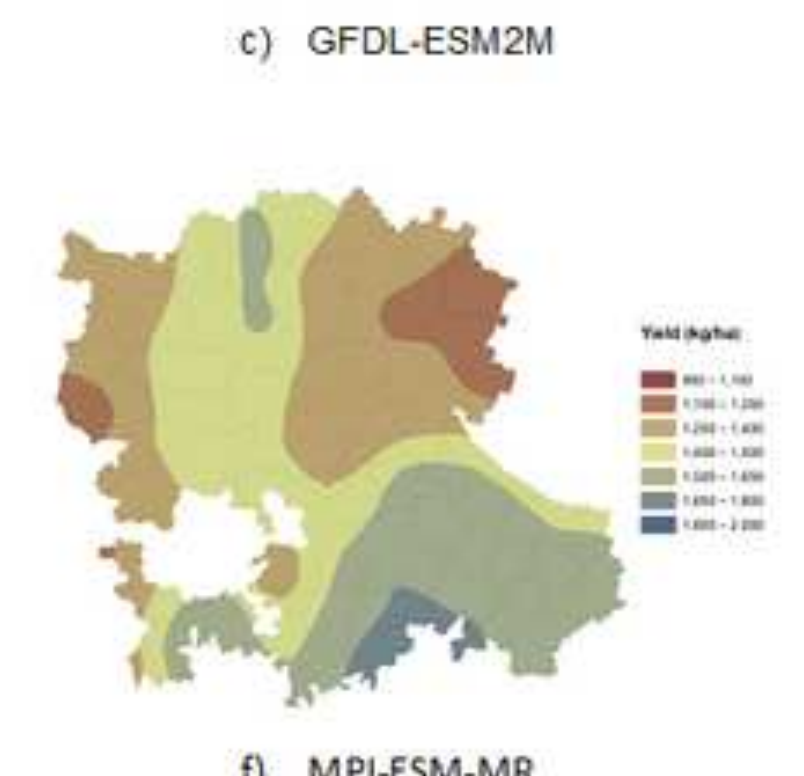

f) MPI-ESM-MR

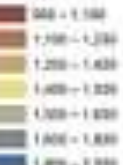

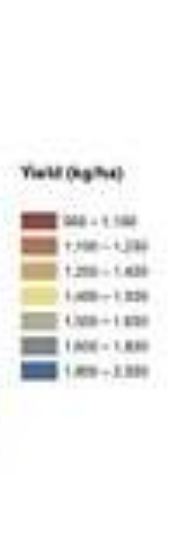




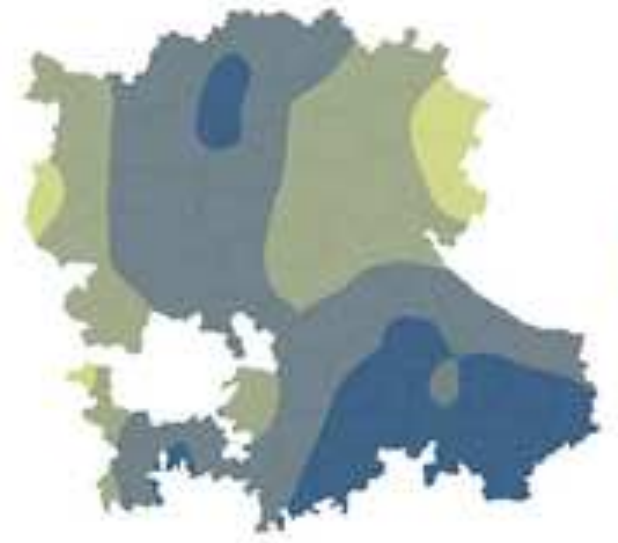

a) Base Line

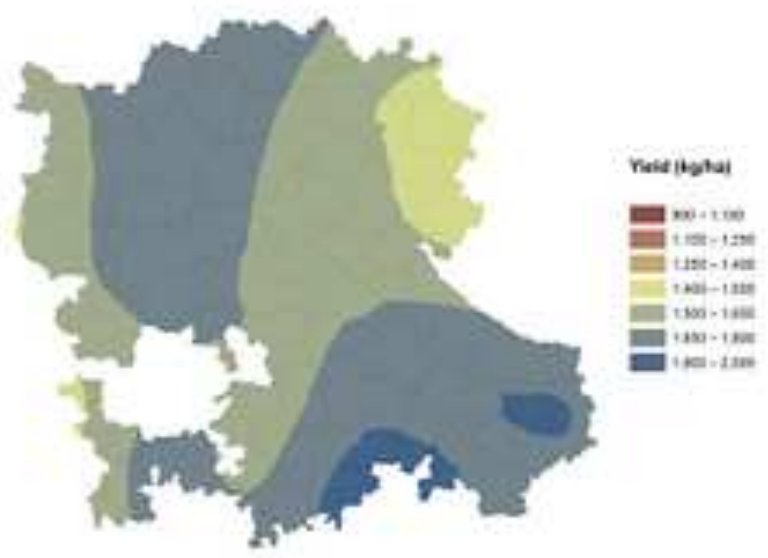

d) HadGEM2-ES

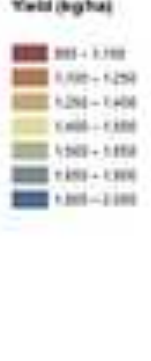

믄 $\cos x$ .us-1, ginarian

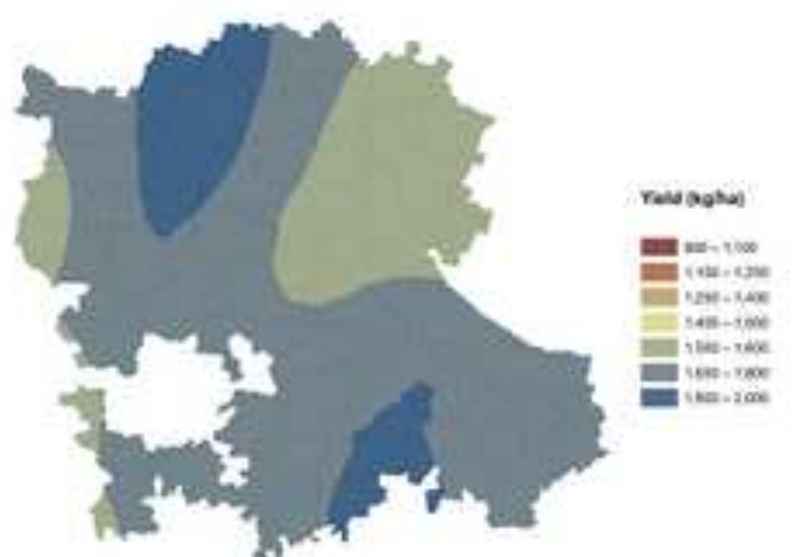

b) $\operatorname{CCSM} 4$

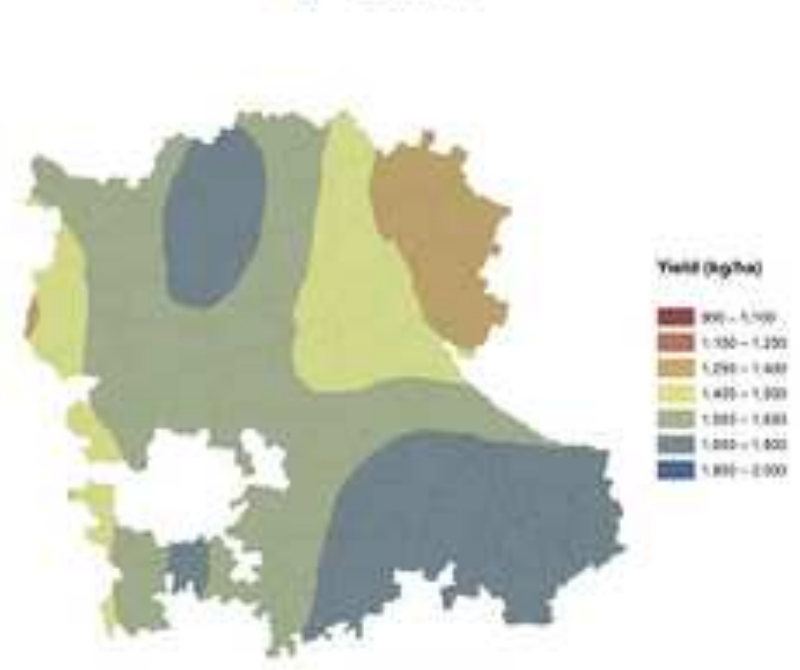

e) MIROC5$$
\text { (1) }
$$

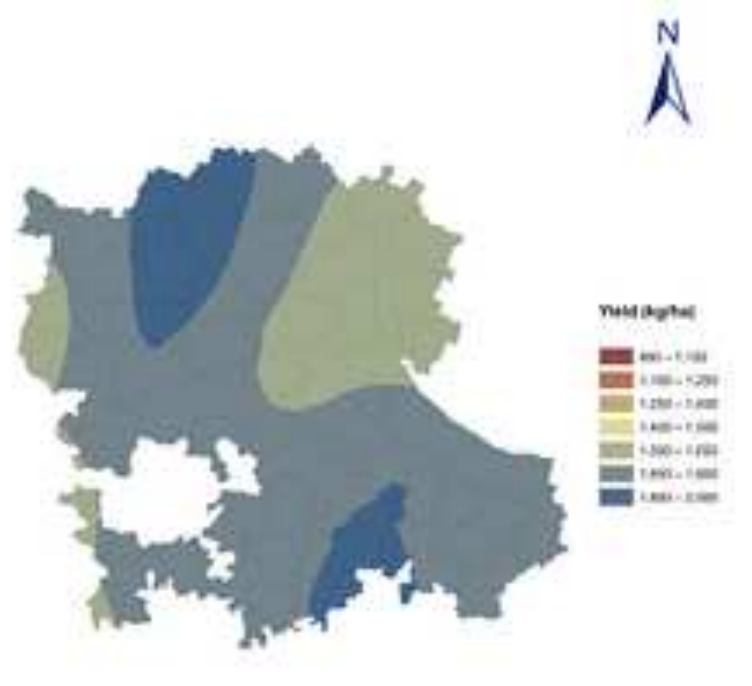

c) GFDL-ESM2M

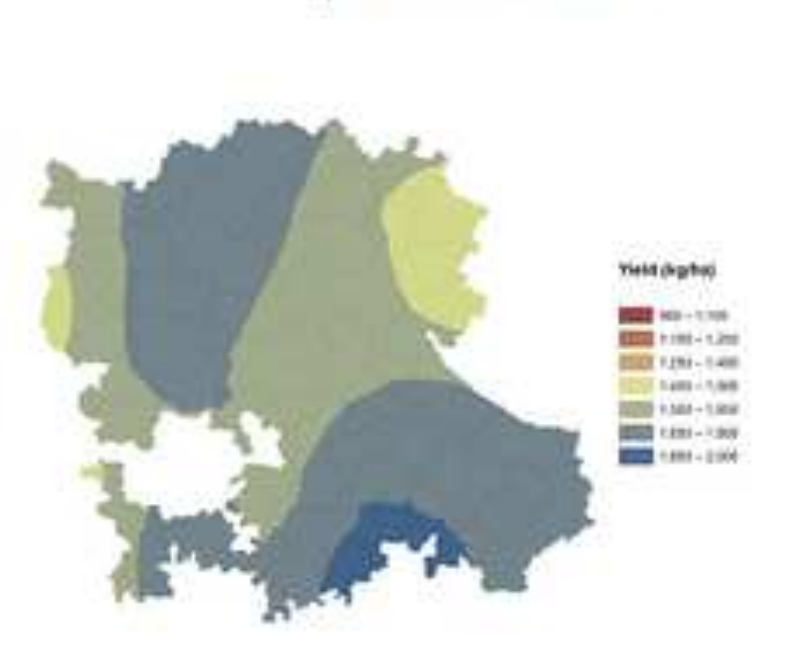

f) MPI-ESM-MR

F 